\title{
Self Evaluation: Building Student Self-awareness and Competence
}

\author{
Denard Lynch \\ University of Saskatchewan \\ denard.lynch@usask.ca
}

This paper discusses the results of two experiments in self assessment and discusses their value in evaluating student consciousness of their competence, and the opportunity to improve self-awareness and competence in students. The data was gathered from two different engineering courses.

The first experiment was conducted in a second-year course on basic electronics and electrical power. As part of the final examination, students were asked to assess their confidence in their answer to each question. The student self-assessment was compared to the actual result in an effort to determine the student's perception of their competence. Student assessment was coded with respect to consciousness and competence.

The second experiment was performed on a midterm examination in engineering ethics and professionalism, a senior course discussing the impact and interaction of the engineering profession on society. Students were given an annotated exemplar and a marking rubric and asked to grade their own midterm submissions. The student assessments were compared to the instructor assessment and again the results were coded with respect to consciousness and competence.

The results showed a contrast between the second-year and senior courses. For the second-year course, 50.3\% were coded as consciously competent or incompetent. In the senior course, $80 \%$ of students were coded as consciously competent.

The comparison of the two results suggest that senior students, given suitable instruction, are more aware of their competence than junior students suggesting that current methods do develop an improved awareness of competence, although other factors may be relevant. It is suggested that student awareness be formally monitored, and results used to modify pedagogy to improve and accelerate consciousness in graduates.

Keywords: student assessment, self assessment, individual, competence

CEEA17; Paper 131

University of Toronto; June 4-7, 2017

-1 of $6-$

\section{INTRODUCTION}

Noel Burch's Learning Stages model based on consciousness and competence [1] suggests that the student progresses through four combinational levels as they develop the skill sets required to practice competently as a professional engineer. These four stages are summarized in Table 1 . The generally accepted progression for learning any new skill starts with being completely unaware that new knowledge or a new skill is required (unconsciously incompetent), and progresses through "consciously incompetent", "consciously competent" and, as mastery is achieved, "unconsciously competent". In industry, the "unconscious - incompetent" is the most dangerous and the most feared combination. It is thus critical that new engineering graduates have at least passed this level before assuming professional responsibilities. Traditional evaluation techniques (e.g. examinations), while potentially providing some feedback, do not formally examine or reinforce student consciousness.

Table 1: Learning Stages Model

\begin{tabular}{|l|l|l|}
\cline { 2 - 3 } \multicolumn{1}{c|}{} & \multicolumn{1}{c|}{ Incompetent } & \multicolumn{1}{c|}{ Competent } \\
\hline \multirow{3}{*}{ Conscious } & $\begin{array}{l}\text { Discovery: } \\
\text { Aware of } \\
\text { knowledge/skill } \\
\text { required, but do not } \\
\text { yet possess }\end{array}$ & $\begin{array}{l}\text { Practice: } \\
\text { In the process of } \\
\text { developing } \\
\text { knowledge/skill }\end{array}$ \\
\hline & $\begin{array}{l}\text { Ignorance: } \\
\text { Unconscious }\end{array}$ & $\begin{array}{l}\text { Mastery: } \\
\text { Achieved a high } \\
\text { level of } \\
\text { lack of knowledge } \\
\text { knowledge/skill } \\
\text { or skill }\end{array}$ \\
\hline
\end{tabular}

While many engineering instructors may use various feedback techniques to improve student learning and performance, there is little evidence that assessment of student learning progression is being monitored. This experiment attempts to assess student progression through this model by comparing self awareness at different stages of an academic program. 


\section{THE RESEARCH QUESTION}

The base assumption is that engineering students enter the program generally unaware of what knowledge or skills they may require to perform as responsible professionals after graduation. Experienced professionals in virtually all areas will often observe that "the more I learn, the more I realize I don't know". This experiment attempts to determine whether, during their academic training, students are progressing along the continuum between being "unconsciously incompetent" and "unconsciously competent", or better. In addition, opportunities for improving self-awareness will be considered.

The hypothesis to be tested is that students become more conscious of their knowledge and skill as they progress through their academic program. This will result in an improved ability to assess their own work in relation to standards.

\section{EXPERIMENTAL DESIGN}

The general objective was to assess students' consciousness with respect to material being presented in a course by evaluating their ability to either predict the correctness of their answer or grade their own papers. An introductory course and a senior course were available to the author, which allowed the opportunity to consider progression through the program.

\subsection{Introductory Course Experimental Setup}

The first experiment was conducted with the final examination in a course on "Basic Electronics and Electrical Power", which is offered as a second year course for mechanical, chemical and environmental engineering programs. As part of the final examination, students were asked to assess their confidence in the answer to each problem by responding, voluntarily, to the question "Do you think your answer to this question is correct (Yes/No/Not Sure)?”. 1771 (43.4\%) valid responses were received. The examination consisted of 24 problems each worth a maximum of 3 marks. Marks were generally assigned as follows:

○ 3: correct answer; correct method

- 2: correct method; minor error resulting in wrong answer

○ 1: some evidence of knowledge in the general area, but not obviously specific to this problem

○ 0: wrong method, wrong answer, or no answer (note: students who did not attempt a problem typically did not respond to the assessment question)
The student self-assessment was compared to the actual result to determine the student's perception of their competence according to the mapping shown in Table 2.

Table 2: Introductory Course Response Mapping

\begin{tabular}{cc|c|c|c|}
\multicolumn{1}{c}{} & \multicolumn{3}{c}{ Student Response } \\
\cline { 2 - 4 } \multicolumn{1}{c|}{} & Yes & No & Not sure \\
\hline $\mathbf{0}$ & U-I & C-I & U-I \\
\hline $\mathbf{1}$ & U-I & C-I & U-I \\
\hline $\mathbf{2}$ & U-I & U-I & C-I \\
\hline $\mathbf{3}$ & C-C & U-I & U-I \\
\hline
\end{tabular}

Student response was coded as either:

○ "Consciously Competent"(C-C) (if they knew they were right).

○ "Consciously Incompetent"(C-I) (if they thought they were wrong and were, or weren't sure but were partially correct)

○ "Unconsciously Incompetent"(U-I) (all other cases; e.g. thought they were right when in fact they were wrong, or vice versa)

Note: It could be argued that "consciously competent" could also be a case of "unconsciously competent", but it is immaterial for the analysis or conclusions in this study. Also note: thinking they were wrong and actually being correct is not a case of being "unconsciously competent".

\subsection{Senior Course Experimental Setup}

The second experiment was conducted with a senior course on professionalism and engineering ethics typically taken by students in the final or penultimate year of their program. Students were advised prior to the midterm examination that they would be asked to grade their own paper, voluntarily, at a later date given a key provided by the instructor. The key consisted of a rubric and an exemplar. Upon completion of their selfassessment, the instructor's grade was revealed to the student.

The midterm examination constituted $15 \%$ of the course grade, and was marked out of a maximum of 15 marks. The exam consisted of an essay-type question, which is inherently more prone to subjectivity and interpretation than deterministic technical questions. An evaluation agreement between the student self-assessment and the instructor assessment of 2 marks (13.3\%) was considered a close match and coded as "consciously competent or incompetent" (e.g. within approximately the same letter grade). This assumed that the student was sufficiently conscious of how their own analysis of the problem was similar to an acceptable standard of performance. Of course, competence versus incompetence would depend on the grade, but agreement would indicate a conscious awareness in either case. A difference of more than 2 marks was interpreted as being 
not conscious of how their performance related to an acceptable standard. Thirty-six $(80 \%)$ responses were received and coded for analysis.

\section{ANALYSIS}

The data from each experiment was analyzed to determine the level of "consciousness" among students, regardless of their level of performance (competence). The two experiments differ in the nature of the subject tasks, but an attempt is made to reduce the data to comparable form.

\subsection{Introductory Course Analysis}

Table 3 summarizes the student responses and the mark assigned for each combination of mark assigned and prediction of correctness. Using the mapping in Table 2 (Section 3.1) shows a total of $890(50.3 \%)$ were considered "consciously competent or incompetent".

Table 3: Introductory Course Results \# Student Response

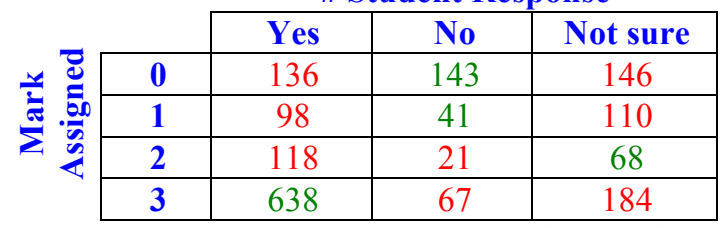

Although the mapping used for the results in Table 3 were considered the most reasonable interpretation of student intent and confidence, other mappings were considered in order to examine the sensitivity of this result.

The first was to include those who thought they were correct but may have missed the full mark due to a minor error (2-Yes) in the "consciously incompetent" category. Since this category could describe those who are still progressing in skill and knowledge but still make mistakes, this is not an unreasonable rationale. Including this category of response as "consciously competent" would increase the "conscious" result to 1008 , or $56.9 \%$. A somewhat similar argument could be made for the "3Not Sure" category (i.e. "consciously competent"), given that those learning may lack the confidence that comes with experience even though they can reasonably assess the knowledge required for a given problem. Including this number instead of "2-Yes" results in a "conscious" total of 1074 or $60.6 \%$.

The second was to take a stricter stance and consider only " 3 -Yes" and "0-No" combinations as legitimately "conscious". In that case, the total drops to 781 or $44.1 \%$.

In summary, the proportion of "consciously competent or incompetent) in this experiment could range from approximately $44 \%$ to $60 \%$, with $50 \%$ being a reasonable representation.

\subsection{Additional Observations}

In the course of this part of the overall experiment, observations were made that may be useful for assessing or improving learning even though not directly relevant to the main objectives of this paper.

The data gathered was for each of the 24 questions on the examination. This provides the opportunity to assess student competence and confidence related to the concepts covered by each. For example, the numbers for "consciously competent" and "consciously incompetent", overall, were $638(36.0 \%)$ and $143(8.1 \%)$ respectively. However, the results for individual questions varied from a low of $8(11.1 \%)$ and a high of $63(81.8 \%)$. This could potentially be a usefully technique for identifying areas for improvement or modification.

\subsection{Senior Course Analysis}

The data collected from the senior course was somewhat different in form. While the introductory course experiment provided a student prediction of the quality of their answer to specific problems for which there was a deterministically correct answer, the senior course provided a comparison of two scores, the instructor's and the student's, in an attempt to assess the self-awareness (consciousness) of the student.

The difference (delta) between student and instructor marks is shown in Table 4 for the 36 submitted samples, and plotted as a histogram in Figure 1.

Table 4: Student - Instructor Frequency

\begin{tabular}{|l|l|l|l|}
\hline Delta & Count & Delta & Count \\
\hline-5 & 0 & 0 & 2 \\
\hline-4.5 & 1 & 0.5 & 3 \\
\hline-4 & 0 & 1 & 5 \\
\hline-3.5 & 1 & 1.5 & 2 \\
\hline-3 & 2 & 2 & 4 \\
\hline-2.5 & 3 & 2.5 & 0 \\
\hline-2 & 2 & 3 & 0 \\
\hline-1.5 & 3 & 3.5 & 0 \\
\hline-1 & 5 & 4 & 0 \\
\hline-0.5 & 3 & 4.5 & 0 \\
\hline
\end{tabular}

The delta is determined by subtracting the instructor assigned mark from the student self-assigned mark (i.e. student mark minus instructor mark= delta). Note the approximately bimodal distribution, with an extended tail on one side. This may possibly be explained by considering the Kruger-Dunning phenomenon [2] if one assumes that the student population consists of either "above average" or "below average" students, two approximately normal distributions would result. It follows from Kruger and Dunning's observations that the

CEEA17; Paper 131

University of Toronto; June 4-7, 2017 
"above average" students would not only underestimate their performance, but would be better able to predict it. The "below average" students, on the other hand, would not only overestimate their performance, but in Kruger and Dunning's words "Not only do they reach mistaken conclusions and make regrettable errors, but their incompetence robs them of the ability to realize it.

"[2], explain the increased variance on the negative side.

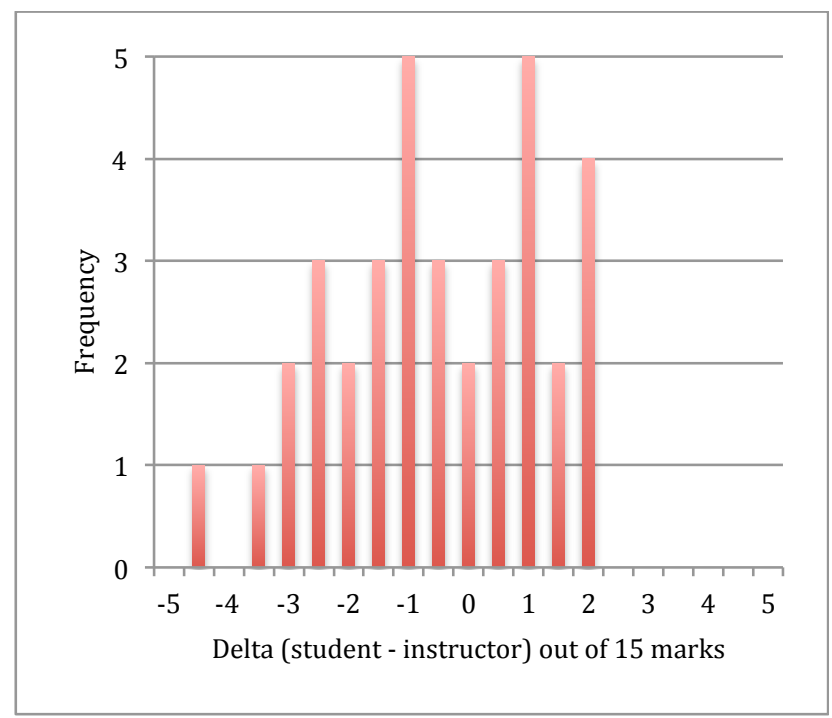

Figure 1: Student - Instructor Frequency

Mapping the quantitative results into the Learning Stages Model matrix requires some decision about what constitutes "unconsciously/consciously competent or incompetent", and how that relates to a mark difference with the instructor's assessment. By selecting some threshold, there is an inherent decision that, similar to the introductory course analysis, that anything outside that threshold must be considered "unconscious incompetence". This is in concert with the objectives of this study: to assess the level of "consciousness" in students, even if they only recognize their lack of competence. Again, the implied assumption is that "unconscious competence" is an advanced level of competence and is inconsequentially indistinguishable from "consciously competent" for the purpose of this analysis.

Reflecting on other work done by the author, evaluation of "soft" material (e.g. essays) by different evaluators, to achieve an agreement in approximately $95 \%$ of cases, will easily require a "bin" of two standard deviations [3]. Even with a reasonably detailed rubric, it is still at least partially subjective and will always vary depending on the evaluator and other circumstances. The standard deviation of the sample data in this case was between $7.2 \%$ (student) and $8.3 \%$ (instructor) (or 1.08 to 1.25 marks). For this analysis, an agreement within two marks (approximately two standard deviations) will be considered a "consciously competent" evaluation; none are coded as "consciously incompetent" in this experiment.

Figure 2 shows the cumulative distribution of the magnitude of the difference between the student and instructor mark assignments. This clearly shows that $80 \%$ of the samples are within two marks and by the selected standard, would be considered "consciously competent" assessments.

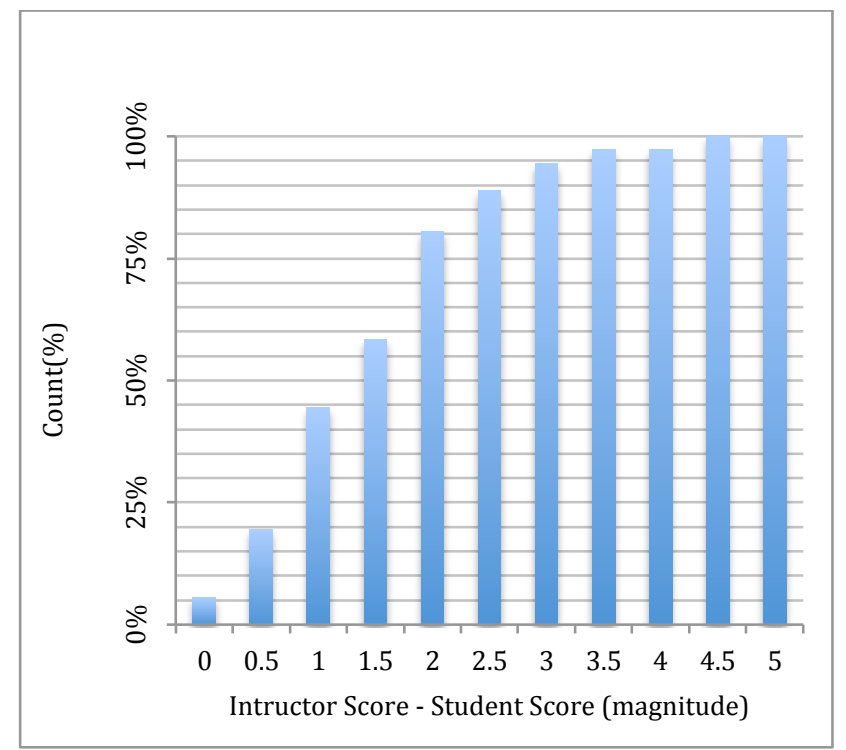

Figure 2: Student - Instructor Agreement (cumulative)

The sensitivity of this result can also be observed in Figure 2. Extending the "agreement" window \pm 0.5 marks ( $\sim 3 \sigma$ would vary the percentage deemed "conscious" by this method from approximately a low of $58 \%$ to a high of $89 \%$. The chosen threshold of two marks seems a reasonable threshold for coding.

\section{CONCLUSIONS}

Recall that the main objective was to determine student progression along Burch's Learning Stages model from an assumed entry level of consciously incompetent to a consciously incompetent or higher level. The analysis is compromised somewhat in experiment two (senior class) because an assessment of "consciously incompetent" was not, or could not, be measured. Nonetheless, evidence exists to support the stated hypothesis at least to some extent.

Table 5 shows the results of analysis of the data from the two experiments included in this study. 
Table 5: Summary of Experimental Results

\begin{tabular}{|l|c|c|c|}
\cline { 2 - 4 } \multicolumn{1}{c|}{} & \% Consciously Incompetent or above \\
\hline Range & Low & Selected & High \\
\hline Exp. 1 & $44 \%$ & $50.3 \%$ & $60 \%$ \\
\hline Exp. 2 & $58 \%$ & $80.0 \%$ & $89 \%$ \\
\hline
\end{tabular}

Assuming reasonable selection of thresholds, the results would indicate that students do indeed progress along the learning continuum from "consciously incompetent" to "consciously incompetent" or higher, during their academic program in preparation for professional engineering.

Additional observations also suggest that the techniques or methods used may have value for assessing or improving student learning and thus their progression to competent professionals.

\section{FUTURE WORK}

An additional observation from the data in Table 4 is that 16 students submitted evaluation the same as, or lower than, the instructor, while 18 were higher than the instructor. This may be an interesting metric to consider for future work, but was not relevant in this study.

Inclusion of student self-assessment in exams could potentially be rich source of data regarding progression to professional self-awareness through programs and thus evidence of desired and required attributes of a professional.

Self-assessment techniques could be assessed throughout a class term to determine efficacy of pedagogical techniques and improve the learning experience of students.

\section{ACKNOWLEDGEMENTS}

The author wish to acknowledge the support of the University of Saskatchewan for providing the means and opportunity for its instructors to explore and enhance their pedagogical skill and knowledge and contribute to the body of knowledge in this area. The author would like to thank co-instructor Andrew Kostiuk for his contributions, support and comments not only for this paper but for his continuing participation and my support in pedagogical research pursuits in general. I would also like to thank Dr. Sean Maw and the other members of the Innovative Teaching and Research in Engineering Education Group at the University of Saskatchewan for their support and suggestions. Finally, the author thanks the students in the subject courses for their patience and voluntary cooperation related to this research.

\section{WORKS CITED}

Linda Adams. (ND, ND) Gordon $\begin{gathered}\text { Training } \\ \text { International. }\end{gathered}$
[Online].

CEEA17; Paper 131

University of Toronto; June 4-7, 2017

-5 of $6-$ http://www.gordontraining.com/free-workplacearticles/learning-a-new-skill-is-easier-said-thandone/\#

[2] Justin Kruger and David Dunning, "Unskilled and unaware of it: How difficulties in recognizing one's own incompetence lead to inflated self-assessments.," Journal of Personality and Social Psychology, vol. Vol 77, no. (6), pp. 1121-1134, Dec 1999, Vol 77(6), Dec 1999, 1121-1134.

[3] Denard Lynch, "Speed Marking: Can intuitive skill replace conscious analysis?," in Proceedings of the Canadian Engineering Education Association, Halifax, 2016, pp. 1-5. 


\section{APPENDIX A: ASSIGNMENT RUBRIC}

Analyze this situation and recommend an appropriate distribution of "blame" for the toddler's death, justifying your response considering principles and material considered in this course. (Note: a concise response is appreciated; a maximum of 500 words suggested as a guide. E.g., this scenario is $\sim 500$ words.)

Grading Rubric:

\begin{tabular}{|c|l|}
\hline \multicolumn{1}{|c|}{ Attribute } & \multicolumn{1}{|c|}{ Performance level } \\
$\begin{array}{c}\text { Selection and } \\
\text { factors to consider }\end{array}$ & $\begin{array}{l}\text { (5) Discussion of reasonable } \\
\text { factors for analysis with } \\
\text { justification of relevance or } \\
\text { perhaps justification for } n o t \\
\text { considering others. A thesis or } \\
\text { abstract indicating key points or } \\
\text { conclusions. }\end{array}$ \\
\hline $\begin{array}{l}\text { Justification of } \\
\text { actions }\end{array}$ & $\begin{array}{l}\text { (7) Strong, logical discussion } \\
\text { leading to clear, supported } \\
\text { conclusions or } \\
\text { recommendations. Uses all } \\
\text { relevant factors chosen to justify } \\
\text { recommendations and covers all } \\
\text { aspects of analysis required by } \\
\text { the question. }\end{array}$ \\
\hline $\begin{array}{l}\text { Composition, } \\
\text { grammar and } \\
\text { readability }\end{array}$ & $\begin{array}{l}\text { (3) Logically and clearly } \\
\text { easily follow. Composition and } \\
\text { grammar did not affect } \\
\text { readability and was accurate and } \\
\text { professional. Factually correct } \\
\text { given the information in the } \\
\text { scenario. Concise with a } \\
\text { minimum of extra words or } \\
\text { redundancies. }\end{array}$ \\
\hline
\end{tabular}

Note: An example response with references were also provided 